\title{
Comparison of waist to height ratio and body indices for prediction of metabolic disturbances in the Korean population: the Korean National Health and Nutrition Examination Survey 2008-2011
}

Seok Hui Kang, Kyu Hyang Cho, Jong Won Park and Jun Young Do*

\begin{abstract}
Background: The aim of the present study of the general population was to identify the best predictor of metabolic risk among the body index variables evaluated with dual-energy $X$-ray absorptiometry (DEXA) or anthropometric indices including the waist to height ratio (WHtR).

Patients and Methods: Data from the Korean National Health and Nutrition Examination Survey 2008-2011 were used for the analyses. As a result, 15,965 participants were included in this study. The body mass (BM) index was calculated as the body weight divided by the height squared. The WHtR was calculated as the waist circumference divided by height. Body composition indices such as lean mass (LM), fat mass (FM), trunk fat mass (TFM), and bone mineral content (BMC) were determined by using DEXA. Skeletal muscle mass (SM) was defined as the sum of the lean soft masses of both extremities. The LM, FM, BMC, TFM, and SM indices were calculated by dividing the total LM, total FM, total BMC, TFM, or SM by the height squared.

Results: The WHtR had the highest area under the curve (AUC) and was the best predictor of metabolic syndrome for both sexes. In addition, the WHtR had the highest AUCs for components of metabolic syndrome (male: AUC 0.823, $95 \%$ confidence interval [Cl] 0.814-0.832; female: AUC $0.870,95 \%$ Cl 0.863-0.877). There was a small statistically significant difference in AUC between WHtR and the other indices. Multivariate logistic regression showed that male participants in the second, third, and fourth quartiles had a $4.0(95 \% \mathrm{Cl}, 3.1-5.2)$, 9.6 (95 \% Cl, 7.5-12.3), and $36.1(95 \% \mathrm{Cl}, 28.0-46.4)$ times increased risk of metabolic syndrome compared with patients in the first quartile and female participants in the second, third, and fourth quartiles had a $4.3(95 \% \mathrm{Cl}, 3.1-6.0), 18.0$ (95 \% Cl, 13.3-24.5), and 58.5 (95 \% Cl, 42.9-79.9) times increased risk of metabolic syndrome compared with patients in the first quartile.
\end{abstract}

Conclusion: Among the BM, FM, LM, SM, TFM, and WHtR indices, WHtR is most useful to predict the presence of metabolic syndrome and insulin resistance in the Korean population.

Keywords: Waist to height ratio, Body composition, Metabolic syndrome, Insulin resistance

\footnotetext{
* Correspondence: jydo@med.yu.ac.kr

Division of Nephrology, Department of Internal Medicine, Yeungnam

University Hospital, 317-1 Daemyung-Dong, Nam-Ku, Daegu 705-717, South

Korea
}

C Biomed Central (c) 2015 Kang et al. Open Access This article is distributed under the terms of the Creative Commons Attribution 4.0 International License (http://creativecommons.org/licenses/by/4.0/), which permits unrestricted use, distribution, and reproduction in any medium, provided you give appropriate credit to the original author(s) and the source, provide a link to the Creative Commons license, and indicate if changes were made. The Creative Commons Public Domain Dedication waiver (http://creativecommons.org/publicdomain/zero/1.0/) applies to the data made available in this article, unless otherwise stated. 


\section{Background}

Metabolic syndrome is a pathologic condition characterized by elevated waist circumference (WC), elevated triglyceride level, reduced high-density lipoprotein cholesterol level, elevated blood pressure, and elevated fasting glucose level [1]. Metabolic syndrome is a risk factor for type 2 diabetes mellitus, and cardiovascular disease is a common health problem in patients with this condition; as a result, metabolic syndrome is associated with a risk of death and complications caused by cardiovascular disease and diabetes mellitus [2, 3]. Early detection and proper management of metabolic syndrome are important for prevention of cardiometabolic problems $[4,5]$.

Metabolic syndrome is closely related to obesity. Body mass index (BMI) and WC are well-known indices of general and abdominal obesity, respectively, and WC is a component of metabolic syndrome. However, various studies have reported that the waist to height ratio (WHtR), which considers ethnicity and height is more closely associated with insulin resistance and clinical outcomes in both adults and children [6-9].

Classic body indices such as BMI, WC, and WHtR, have been used to assess metabolic problems and have several advantages as simple rapid screening tools. However, they do not provide the distribution between skeletal muscle mass and fat. Body composition analyzers such as multi-frequency bioimpedance analysis and dual-energy X-ray absorptiometry (DEXA), can differentiate between muscle mass and fat and the distribution between limb and trunk.

Recent studies using body composition analyzers have reported that fat mass (FM) is positively correlated with metabolic syndrome [10-16]. However, some large-scale studies did not show that indices using body composition analyzers are superior to classic indices [17-19]. The aim of the present study of the general population was to identify the best predictor of metabolic risk among the body index variables evaluated with DEXA or anthropometric indices including the WHtR.

\section{Patients and Methods}

\section{Study population}

Data from the Korean National Health and Nutrition Examination Survey (KNHANES) 2008-2011 were used for the analyses. The KNHANES is a nationwide, multistage stratified survey of a representative sample of the entire South Korean population conducted by the Korea Centers for Disease Control and Prevention. The total number of participants in KNHANES was 37,753. Those who had no information regarding renal function and/or metabolic markers $(n=14,533)$, had no information regarding body composition $(n=6,019)$, or were younger than 18 years of age $(n=1,236)$ were excluded. As a result, 15,965 participants were included in this study. This study was approved by the institutional review board of Yeungnam University Hospital (YUH-14-0454-O56). The board waived the need for informed consent.

\section{Study variables}

Clinical and laboratory data collected during the health examination included age, sex, education level, smoking behavior, mean daily alcohol intake, physical activity, WC $(\mathrm{cm})$, WHtR, BMI $\left(\mathrm{kg} / \mathrm{m}^{2}\right)$, lean mass $(\mathrm{LM})$ index $\left(\mathrm{kg} / \mathrm{m}^{2}\right)$, FM index $\left(\mathrm{kg} / \mathrm{m}^{2}\right)$, trunk FM (TFM) index $\left(\mathrm{kg} / \mathrm{m}^{2}\right)$, skeletal muscle mass $(\mathrm{SM})$ index $\left(\mathrm{kg} / \mathrm{m}^{2}\right)$, bone mineral content (BMC) index $\left(\mathrm{kg} / \mathrm{m}^{2}\right)$, systolic blood pressure $(\mathrm{mmHg})$, diastolic blood pressure $(\mathrm{mmHg})$, fasting glucose level $(\mathrm{mg} / \mathrm{dL})$, total cholesterol level $(\mathrm{mg} / \mathrm{dL})$, triglyceride level $(\mathrm{mg} / \mathrm{dL})$, high-density lipoprotein $(\mathrm{mg} / \mathrm{dL})$, and estimated glomerular filtration rate (eGFR) $\left(\mathrm{mL} / \mathrm{min} / 1.73 \mathrm{~m}^{2}\right)$.

Fasting glucose, total cholesterol, triglyceride, highdensity lipoprotein levels were measured by a Hitachi Automatic Analyzer 7600 (Hitachi, Japan) by the enzymatic method (Sekisui Co., Japan). Serum creatinine level was measured by using a Hitachi Automatic Analyzer (alkaline picrate, Jaffé kinetic). The eGFR was calculated using the Chronic Kidney Disease Epidemiology Collaboration equation [20]. Chronic kidney disease was defined as an eGFR $<60 \mathrm{~mL} / \mathrm{min} / 1.73 \mathrm{~m}^{2}$ or dipstick proteinuria $(\geq 1+)$. Physical activity was assessed by selfreported questionnaires that examined frequency, intensity, and time per day spent on physical activity. We calculated metabolic equivalent-minutes per week (MET $\mathrm{min} / \mathrm{wk}$ ) using a physical activity calculating International Physical Activity Questionnaire and divided into 3 groups (<3000 MET min/wk, 3000-6000 MET min/wk, and $\geq 6000 \mathrm{MET} \mathrm{min} / \mathrm{wk}$ ) [21]. We defined smoking status in 2 respects: "smoking status" and "smoking amount" (PYR, average daily smoking amount [pack] $\times$ smoking period [year]). The cohorts were divided into 4 groups accordingly: heavy smoker (current smoker, $\geq 30$ PYR), intermediate smoker (current smoker, <30 PYR), ex-smoker, and non-smoker [22]. Mean daily alcohol intake was defined as the Korean version of a "standard drinking", which was based on WHO classification [23, 24]. We classified mean daily alcohol intake into 3 categories: abstinence (not having had a drink containing alcohol within the last year), moderate drinking (women, 0.1$19.99 \mathrm{~g}$ pure alcohol/day; men, 0.1-39.99 g pure alcohol/day), and heavy drinking (women, $\geq 20 \mathrm{~g}$ pure alcohol/day; men, $\geq 40 \mathrm{~g}$ pure alcohol/day). Weight and height were measured by well-trained medical professionals. Standing height was measured with the subject facing directly ahead with shoes off, feet together, arms by the sides, and heels, buttocks, and upper back in contact with the wall using a SECA 225 (SECA, Hamburg, Germany). Weight was 
measured using a GL-6000-20 scale (Cass, Seoul, Korea). WC was measured at the midpoint between the bottom of the rib cage and the top of the iliac crest. WHtR was calculated as WC divided by height. Body composition measurements such as LM, FM, and BMC, were determined by using DEXA (QDR 4500A; Hologic Inc., Waltham, MA, USA). SM was defined as the sum of the lean soft masses of both extremities. The LM, FM, BMC, TFM, and SM indices were calculated by dividing the total LM, total FM, total BMC, TFM, or SM by the height squared $\left(\mathrm{kg} / \mathrm{m}^{2}\right)$.

Metabolic syndrome was defined by the current criteria in the National Cholesterol Education Program Adult Treatment Panel III guidelines [1]. Elevated blood pressure was defined as a systolic or diastolic blood pressure of $\geq 130 / 85 \mathrm{mmHg}$, a self-reported history of hypertension, or the use of anti-hypertensive drugs. Elevated blood glucose was defined as a fasting blood glucose level $\geq 100 \mathrm{mg} / \mathrm{dL}$ or a self-reported history of diabetes mellitus. A low high-density lipoprotein cholesterol level was defined as $<40 \mathrm{mg} / \mathrm{dL}$ in men and $<50 \mathrm{mg} / \mathrm{dL}$ in women. Elevated triglyceride was defined as a serum triglyceride $\geq 150 \mathrm{mg} / \mathrm{dL}$. Abdominal obesity was defined as a WC $>90 \mathrm{~cm}$ in men and $>80 \mathrm{~cm}$ in women. Metabolic syndrome was defined as the presence of $\geq 3$ components of metabolic syndrome.

\section{Statistical analyses}

The data were analyzed by SPSS version 19 (SPSS, Chicago, IL, USA). The distribution of continuous variables was checked by using the KolmogorovSmirnov test. Non-parametric variables were expressed as median (interquartile range) and compared by using the Mann-Whitney U-test. Categorical variables were expressed as counts and percentages. Pearson $x^{2}$ test or Fisher exact test was used to analyze categorical variables. Multivariate logistic regression was used to estimate the odds ratios, and the $95 \%$ confidence intervals were used to determine the relationship between variables and metabolic syndrome. Covariates that were considered potential confounders (age, smoking, physical activity, and mean daily alcohol intake) were included in multivariate models. Model 1 was unadjusted, model 2 was adjusted for age, smoking, physical activity, and mean daily alcohol intake. Metabolic syndrome components were analyzed using analysis of covariance. Discrimination, which is the ability of the model to differentiate between participants who have metabolic syndrome and those who do not, was examined using the area under the receiver operating characteristic curve (AUROC). AUROC analysis was also performed to calculate cutoff values, sensitivity, and specificity. The best cutoff risk point was defined from the maximum of the Youden index in the AUROC. The statistical significance between the areas under indices receiver operating characteristic curves was calculated by the DeLong method. The AUROC was calculated by using MedCalc version 11.6.1.0 (MedCalc, Mariakerke, Belgium). The level of statistical significance was set at $P<0.05$.

\section{Results}

\section{Baseline characteristics of participants}

The mean age of the study participants was 48 (36-62) years for men $(n=6875)$ and $48(36-61)$ years for women $(n=9090)$ (Table 1$)$. The number of participants with education levels of up to elementary school, middle school, high school, and college or higher was 1,263 (18.4 \%), 871 (12.7\%), 2,471 (35.9\%), and 2,231 (32.5\%), respectively, in men, and 3,033 (33.4\%), 965 (10.6\%), 2,975 (32.7\%), and 2,070 (22.8\%), respectively, in women $(P<0.001)$. The education level was higher in men than in women. The male participants had higher body indices, including WC, WHtR, BMI, LM index, BMC index, SM index, and TFM index, than the female participants. The male participants also had significantly higher blood pressure, fasting glucose levels, triglyceride levels, and lower levels of high-density lipoprotein cholesterol than the female participants. In addition, the male participants had a higher prevalence of heavy drinking, current smoking, and chronic kidney disease than the female participants.

\section{Comparison of the prediction of metabolic syndrome among the body indices}

The body indices for prediction of metabolic syndrome were explored using AUROC curves, as shown in Additional file 1: Table S2. The WHtR had the highest area under the curve (AUC) (male: 0.823, 95 \% CI 0.814-0.832; female: $0.870,95 \%$ CI 0.863-0.877) and was the best predictor of metabolic syndrome for both sexes. The sensitivity of predicting metabolic syndrome by WHtR was $74.0 \%$ for the male participants and $83.3 \%$ for the female participants, and the specificity was $75.8 \%$ for the male participants and $76.5 \%$ for the female participants. Considering the indices with an AUC $<0.6$ to be poor measures, the BMC index had the lowest AUC $(<0.6)$ and was poorest measure in predicting metabolic syndrome in both sexes.

In addition, the WHtR had the highest AUCs for components of metabolic syndrome, including elevated fasting glucose level, elevated blood pressure, elevated triglyceride level, and reduced high-density lipoprotein cholesterol level. In males, the SM and $\mathrm{BMC}$ indices were poor measures in predicting all metabolic syndrome components (Table 2). The LM 
Table 1 Clinical characteristics of the participants

\begin{tabular}{|c|c|c|c|}
\hline Characteristics & Males $(n=6875)$ & Females $(n=9090)$ & $P$ value* \\
\hline Age & $48(36-62)$ & $48(36-61)$ & 0.748 \\
\hline WC $(\mathrm{cm})$ & $84.2(78.2-90.2)$ & $77.8(71.1-85.0)$ & $<0.001$ \\
\hline WHtR & $0.497(0.459-0.533)$ & $0.497(0.450-0.548)$ & $<0.001$ \\
\hline BMI $\left(\mathrm{kg} / \mathrm{m}^{2}\right)$ & $23.9(21.8-25.9)$ & $23.0(20.9-25.4)$ & $<0.001$ \\
\hline LM index $\left(\mathrm{kg} / \mathrm{m}^{2}\right)$ & $17.4(16.3-18.6)$ & $14.5(13.4-15.6)$ & $<0.001$ \\
\hline FM index $\left(\mathrm{kg} / \mathrm{m}^{2}\right)$ & $5.3(4.0-6.5)$ & $7.6(6.2-9.1)$ & $<0.001$ \\
\hline BMC index $\left(\mathrm{kg} / \mathrm{m}^{2}\right)$ & $0.88(0.81-0.95)$ & $0.80(0.71-0.88)$ & $<0.001$ \\
\hline $\mathrm{SM}$ index $\left(\mathrm{kg} / \mathrm{m}^{2}\right)$ & $7.6(7.1-8.2)$ & $5.8(5.4-6.3)$ & $<0.001$ \\
\hline TFM index $\left(\mathrm{kg} / \mathrm{m}^{2}\right)$ & $8.7(8.1-9.3)$ & $7.5(6.9-8.1)$ & $<0.001$ \\
\hline SBP $(\mathrm{mmHg})$ & 116.5 (107.5-128.5) & 111.9 (101.9-126.9) & $<0.001$ \\
\hline $\mathrm{DBP}(\mathrm{mmHg})$ & $76.5(69.3-84.5)$ & $71.9(66.9-78.9)$ & $<0.001$ \\
\hline Fasting glucose (mg/dL) & $94(88-103)$ & 92 (86-99) & $<0.001$ \\
\hline Total cholesterol (mg/dL) & $183(161-208)$ & $185(163-210)$ & $<0.001$ \\
\hline HDL cholesterol (mg/dL) & $48(41-56)$ & $53(45-62)$ & $<0.001$ \\
\hline Triglyceride (mg/dL) & $123(84-187)$ & $94(65-140)$ & $<0.001$ \\
\hline Smoking & & & $<0.001$ \\
\hline Heavy smoker & $761(11.1 \%)$ & $28(0.3 \%)$ & \\
\hline Intermediate smoker & 3645 (53.0 \%) & 778 (8.6 \%) & \\
\hline Ex-smoker & 1059 (15.4 \%) & $185(2.0 \%)$ & \\
\hline Non-smoker & 1279 (18.6 \%) & 7935 (87.3 \%) & \\
\hline No data & $42(0.6 \%)$ & $68(0.7 \%)$ & \\
\hline Mean daily alcohol intake & & & $<0.001$ \\
\hline Abstinence & 1127 (16.4 \%) & 3387 (37.3 \%) & \\
\hline Moderate drinking & 4107 (59.7 \%) & $5138(56.5 \%)$ & \\
\hline Heavy drinking & 1591 (23.1 \%) & $494(5.4 \%)$ & \\
\hline No data & $50(0.7 \%)$ & $71(0.8 \%)$ & \\
\hline Exercise & & & $<0.001$ \\
\hline$\geq 6000 \mathrm{MET} \mathrm{min} / \mathrm{wk}$ & $1666(24.2 \%)$ & 1479 (16.3 \%) & \\
\hline $3000 \sim 6000 \mathrm{MET} \mathrm{min} / \mathrm{wk}$ & 1466 (21.3\%) & 1456 (16.0\%) & \\
\hline$<3000 \mathrm{MET} \mathrm{min} / \mathrm{wk}$ & $3672(53.4 \%)$ & $6039(66.4 \%)$ & \\
\hline No data & $71(1.0 \%)$ & $116(1.3 \%)$ & \\
\hline Metabolic syndrome & 2159 (31.4 \%) & 2932 (32.3 \%) & 0.258 \\
\hline $\mathrm{eGFR}\left(\mathrm{mL} / \mathrm{min} / 1.73 \mathrm{~m}^{2}\right)$ & $93.7(83.2-104.6)$ & $101.3(89.0-113.9)$ & $<0.001$ \\
\hline CKD & 307 (4.5\%) & 283 (3.1\%) & $<0.001$ \\
\hline
\end{tabular}

Data are expressed as numbers (percentages) for categorical variables and median (interquartile range) for continuous variables

Abbreviations: WC waist circumference; WHtR waist to height ratio; $B M I$ body mass index; $L M$ lean mass; $F M$ fat mass; $B M C$ bone mineral content; $S M$ skeletal muscle mass; TFM trunk fat mass; SBP systolic blood pressure; DBP diastolic blood pressure; $H D L$ high-density lipoprotein; $M E T$ min/wk metabolic equivalent-minutes per week; eGFR estimated glomerular filtration rate; CKD chronic kidney disease

*Statistical significance was tested by using the Mann-Whitney U-test for continuous variables and Pearson $\mathrm{X}^{2}$ test or Fisher exact test for categorical variables

index was predictive for only elevated triglyceride level among the metabolic syndrome components. In females, the BMC index was a poor measure in predicting all metabolic syndrome components. The SM index was predictive for only elevated fasting glucose and blood pressure levels among the metabolic syndrome components.

\section{Presence of metabolic syndrome according to WHtR quartiles}

The WHtRs were divided into 4 quartiles. The quartiles for male participants were as follows: first quartile (Q1), $\leq 0.4603$; second quartile (Q2), 0.4604-0.4981; third quartile (Q3), 0.4982-0.5343; and fourth quartile (Q4), $\geq 0.5344$. The quartiles for the female participants 
Table 2 The AUROC of each of the indices for the presence of metabolic syndrome components

\begin{tabular}{lllll}
\hline Variables & Elevated FG & Elevated BP & Elevated TG & Decreased HDL-C \\
\hline Males & AUC $(95 \% \mathrm{Cl})$ & AUC $(95 \% \mathrm{Cl})$ & AUC $(95 \% \mathrm{Cl})$ & AUC (95 \% Cl) \\
BMI & $0.611(0.600-0.623)^{*}$ & $0.615(0.603-0.627)^{*}$ & $0.672(0.660-0.683)^{*}$ & $0.634(0.622-0.645)^{*}$ \\
FM index & $0.613(0.601-0.624)^{*}$ & $0.625(0.614-0.637)^{*}$ & $0.679(0.668-0.690)^{* *}$ & $0.642(0.630-0.653)^{* *}$ \\
LM index & $0.571(0.560-0.583)^{*}$ & $0.569(0.557-0.581)^{*}$ & $0.611(0.599-0.623)^{*}$ & $0.587(0.575-0.599)^{*}$ \\
BMC index & $0.536(0.525-0.548)^{*}$ & $0.517(0.505-0.529)^{*}$ & $0.531(0.519-0.543)^{*}$ & $0.540(0.528-0.552)^{*}$ \\
SM index & $0.505(0.493-0.517)^{*}$ & $0.506(0.494-0.518)^{*}$ & $0.572(0.561-0.584)^{*}$ & $0.546(0.534-0.558)^{*}$ \\
TFM index & $0.620(0.609-0.632)^{*}$ & $0.615(0.604-0.627)^{*}$ & $0.631(0.619-0.642)^{*}$ & $0.614(0.602-0.625)^{*}$ \\
WHtR & $0.685(0.674-0.696)$ & $0.677(0.665-0.688)$ & $0.693(0.682-0.704)$ & $0.657(0.644-0.667)$ \\
Females & AUC (95\% Cl) & AUC $(95 \% \mathrm{Cl})$ & AUC (95 \% Cl) & AUC (95 \% Cl) \\
BMI & $0.689(0.679-0.698)^{*}$ & $0.693(0.683-0.703)^{*}$ & $0.688(0.678-0.698)^{*}$ & $0.640(0.630-0.650)^{*}$ \\
FM index & $0.665(0.655-0.674)^{*}$ & $0.676(0.666-0.686)^{*}$ & $0.680(0.670-0.689)^{*}$ & $0.627(0.617-0.637)^{*}$ \\
LM index & $0.670(0.660-0.680)^{*}$ & $0.670(0.660-0.679)^{*}$ & $0.650(0.640-0.660)^{*}$ & $0.621(0.611-0.631)^{*}$ \\
BMC index & $0.550(0.540-0.560)^{*}$ & $0.625(0.615-0.635)^{*}$ & $0.570(0.559-0.580)^{*}$ & $0.534(0.524-0.544)^{*}$ \\
SM index & $0.615(0.605-0.625)^{*}$ & $0.604(0.594-0.614)^{*}$ & $0.597(0.587-0.607)^{*}$ & $0.595(0.585-0.605)^{*}$ \\
TFM index & $0.690(0.680-0.699)^{*}$ & $0.684(0.674-0.693)^{*}$ & $0.664(0.654-0.674)^{*}$ & $0.621(0.611-0.631)^{*}$ \\
WHtR & $0.735(0.726-0.744)$ & $0.776(0.768-0.785)$ & $0.738(0.729-0.747)$ & $0.671(0.662-0.681)$ \\
\hline
\end{tabular}

Abbreviations: $A U R O C$ area under the receiver operating characteristic curve; $F G$ fasting glucose; $B P$ blood pressure; $T G$ triglyceride; $H D L-C$ high density lipoprotein cholesterol; $A U C$ area under the curve; $C I$ confidence interval; $B M I$, body mass index; $F M$ fat mass; $L M$ lean mass; $B M C$ bone mineral content; $S M$ skeletal muscle mass; TFM trunk fat mass; WHtR waist to height ratio

${ }^{*} P<0.001$ compared with the WHtR

${ }^{* *} P<0.01$ compared with the WHtR

were as follows: Q1, $\leq 0.4520$; Q2, 0.4521-0.5002; Q3, $0.5003-0.5510$; and $\mathrm{Q} 4, \geq 0.5511$. In model 2, male participants in Q2, Q3, and Q4 had a 4.0 (95\% CI 3.1-5.2), 9.6 (95 \% CI 7.5-12.3), and 36.1 (95\% CI 28.0-46.4) times increased risk of metabolic syndrome compared with patients in Q1 and female participants in the Q2, Q3, and Q4 had a 4.3 (95 \% CI 3.1-6.0), 18.0 (95 \% CI 13.3-24.5), and 58.5 (95 \% CI 42.9-79.9) times increased risk of metabolic syndrome compared with patients in Q1 (Table 3). In addition, WHtR quartiles had highest odd ratios for metabolic syndrome among BMI, FM index, TFM index, and WHtR in both Model 1 and Model 2.

The patients had more metabolic syndrome components on both univariate and multivariate analyses as the WHtR quartiles increased (Table 4). In addition, the WHtR quartiles had the highest odds ratios for predicting all metabolic syndrome components except elevated blood pressure in males (Additional file 1: Table S3). Logistic regression analyses by using a cut-off value of $\mathrm{WHtR}<0.5$ as an international guideline showed a significant association between WHtR $<0.5$ and metabolic syndrome or metabolic syndrome components (Additional file 1: Table S4).

\section{Discussion}

The present study demonstrates that WHtR had the highest AUC and was the best predictor of metabolic syndrome and components of metabolic syndrome for both sexes. Univariate and multivariate analyses revealed that WHtR quartiles were associated with metabolic syndrome in the general population. In addition, the WHtR quartiles had the highest odds ratio for predicting most metabolic syndrome components (elevated fasting glucose, blood pressure, triglyceride level, and decreased high-density lipoprotein level) among the other indices in both sexes. Logistic regression analyses with a cut-off value of $\mathrm{WHtR}<0.5$ as an international guideline showed a significant association with metabolic syndrome or metabolic syndrome components.

Obesity is a well-known risk factor for and component of metabolic syndrome. Central visceral fat has shown stronger associations with cardiovascular disease risk and metabolic syndrome than subcutaneous fat $[25,26]$. Previous studies have demonstrated that WC is closely correlated to reference methods such as computed tomography or magnetic resonance imaging and is a more predictive surrogate for metabolic syndrome than BMI $[6,7,9,27,28]$. Height is inversely associated with cholesterol level, and WC would be needed to adjust for height [29]. Therefore, WHtR may be a more predictive measure than classic body indices such as WC and BMI. A meta-analysis showed the superiority of WHtR [9].

The present study compared the anthropometric (WHtR and BMI) and body composition indices. Our results shows that body indices using a body composition analyzer have no advantage over classic anthropometric indices. Our results showed that WHtR had the highest 
Table 3 Odds ratios for metabolic syndrome according to the quartiles of variable indices

\begin{tabular}{|c|c|c|c|c|}
\hline & Q1 & Q2 & Q3 & Q4 \\
\hline \multicolumn{5}{|l|}{ Males } \\
\hline \multicolumn{5}{|l|}{ Model 1} \\
\hline BMI & - & $3.0(2.4-3.7)$ & $6.0(5.0-7.4)$ & $17.3(14.2-21.0)$ \\
\hline FM index & - & 3.7 (3.0-4.6) & $7.9(6.4-9.7)$ & $16.5(13.5-20.3)$ \\
\hline TFM index & - & $2.2(1.8-4.8)$ & $4.0(3.4-4.8)$ & $9.6(8.1-11.5)$ \\
\hline $\mathrm{WHtR}$ & - & $4.4(3.4-5.7)$ & $11.5(9.0-14.7)$ & $44.3(34.6-56.7)$ \\
\hline \multicolumn{5}{|l|}{ Model 2} \\
\hline BMI & - & $3.5(2.8-4.3)$ & $7.7(6.2-9.5)$ & $28.3(22.7-35.1)$ \\
\hline FM index & - & $3.8(3.0-4.7)$ & $8.1(6.6-10.0)$ & $20.0(16.1-24.8)$ \\
\hline TFM index & - & $2.5(2.1-3.1)$ & $4.7(3.9-5.7)$ & $12.3(10.2-14.9)$ \\
\hline $\mathrm{WHtR}$ & - & $4.0(3.1-5.2)$ & $9.6(7.5-12.3)$ & $36.1(28.0-46.4)$ \\
\hline \multicolumn{5}{|l|}{ Females } \\
\hline \multicolumn{5}{|l|}{ Model 1} \\
\hline BMI & - & $3.8(3.1-4.7)$ & $9.9(8.2-12.0)$ & $27.1(22.3-32.8)$ \\
\hline FM index & - & $3.2(2.7-3.9)$ & $7.7(6.5-9.2)$ & $18.7(15.6-22.2)$ \\
\hline TFM index & - & $2.6(2.2-3.1)$ & $5.5(4.7-6.5)$ & $14.9(12.7-17.5)$ \\
\hline $\mathrm{WH} \mathrm{tR}$ & - & $6.2(4.6-8.5)$ & $33.0(24.5-44.4)$ & $129.3(95.7-174.6)$ \\
\hline \multicolumn{5}{|l|}{ Model 2} \\
\hline BMI & - & $3.4(2.7-4.2)$ & $8.3(6.7-10.2)$ & $25.8(20.8-32.0)$ \\
\hline FM index & - & $3.5(2.8-4.3)$ & $7.0(5.8-8.6)$ & $18.4(15.0-22.4)$ \\
\hline TFM index & - & $2.2(1.8-2.6)$ & $4.1(3.4-4.9)$ & $12.4(10.3-14.9)$ \\
\hline $\mathrm{WHtR}$ & - & $4.3(3.1-6.0)$ & $18.0(13.3-24.5)$ & $58.5(42.9-79.9)$ \\
\hline
\end{tabular}

Model 1 was unadjusted, whereas model 2 was adjusted for age, mean daily alcohol intake, smoking, and physical activity. Variables were expressed as odds ratio (95\% confidence interval), and odds ratios were calculated for Q1 Abbreviations: BMI body mass index; FM fat mass; TFM trunk fat mass; WHtR waist to height ratio; $\mathrm{Cl}$ confidence interval; $\mathrm{Q} 1$ first quartile; $Q 2$ second quartile; Q3 third quartile; Q4 fourth quartile

Statistical significance was defined as $P<0.001$ for all analyses

AUC for predicting metabolic syndrome among other body indices including BMI, FM, LM, SM, BMC, and TFM for both sexes. Logistic regression analyses showed that the WHtR quartiles had the highest odds ratio for predicting metabolic syndrome or each component among the BMI, FM index, TFM index, and WHtR. There was a significant difference in numbers of metabolic syndrome components using the general linear model and these data compensate for the weakness of the dichromatic category for metabolic syndrome. Our results show that body indices measured using the body composition analyzer have no advantage over classic anthropometric indices. Zhang et al. enrolled Asians and showed that the sensitivity and specificity of WHtR were $75.9 \%$ and $52.7 \%$ in males and $67.8 \%$ and $62.5 \%$ in females, respectively [18]. The values in their study were lower than those in the present study, while the cut-off values in their study were similar to those in the present study.
Classic body indices cannot distinguish between fat and other components. Body composition analyzers such as bioimpedance analysis and DEXA, measure FM and freefat mass, which include BMC and LM. These indices may be a more optimal marker for prediction of metabolic syndrome or insulin resistance than classic indices. Kim et al. showed that the FMI evaluated with bioimpedance analysis was the most strongest predictor of metabolic syndrome among Korean men [14]. Namwongprom et al. enrolled Thai adults and showed that the android-to-gynoid FM ratio calculated by using DEXA was more predictive in the diagnosis of metabolic syndrome than either the WC or BMI [15]. A previous study in a Turkish population showed that the WHtR is the most predictive indicator among the anthropometric indices; however, visceral fat measured with bioimpedance analysis is a more sensitive variable than the WHtR [16]. However, many studies did not show stronger associations between body composition indices and metabolic syndrome and/or components of metabolic syndrome than classic indices [18, 30-34]. Bioimpedance analysis or DEXA can measure the exact FM. Although FM is associated with development of metabolic syndrome, there have been controversies regarding the advantage of FM in prediction of metabolic syndrome. Many studies have shown that FM has no advantage over classic body indices [18, 30-32]. Some recent studies enrolled migrant Asian Indian, Chinese, or multiethnics participants and compared various anthropometric indices with indices measured with DEXA [17-19]. However, those studies did not show a superiority of the indicators measured with body composition analyzers over either the WC or WHtR. Bosy-Westphal et al. suggested that the inaccuracies of impedance measurement may be associated with discrepancies among studies [35]. DEXA is a reference method for measurement of FM. However, simple trunk or total FM cannot differentiate between subcutaneous and visceral fat. In addition, previous studies have shown that an increase in LM may be associated with an increase in the prevalence of metabolic syndrome. LM plays an important role in maintenance of systemic glucose metabolism [36]. Many clinicians believe that LM may be a protective effect of development of metabolic syndrome. Previous studies have shown that an increase in LM is positively associated with the risk of developing insulin resistance and metabolic syndrome [29, 33]. Although the exact mechanism for positive correlation remains poorly understood, its association may be linked to a paradoxical decrease in LM to metabolize glucose for energy as LM increases [37]. These findings demonstrate that indices using body composition analyzers have no advantage over classic body indices.

A systematic review of many prospective or crosssectional studies and involving many ethnic groups suggested that 0.5 is an appropriate boundary value for 
Table 4 Number of metabolic syndrome components by the WHtR quartile

\begin{tabular}{|c|c|c|c|c|}
\hline & Q1 & Q2 & Q3 & Q4 \\
\hline \multicolumn{5}{|l|}{ Males } \\
\hline \multicolumn{5}{|l|}{ Model 1} \\
\hline Mean $(95 \% \mathrm{Cl})^{*}$ & $0.711(0.657-0.765)$ & $1.369(1.315-1.423)$ & $2.050(1.996-2.104)$ & $3.067(3.013-3.121)$ \\
\hline \multicolumn{5}{|l|}{ Model 2} \\
\hline Mean* & $0.830(0.774-0.885)$ & $1.387(1.334-1.441)$ & $1.998(1.945-2.052)$ & $2.997(2.923-3.032)$ \\
\hline \multicolumn{5}{|l|}{ Model 3} \\
\hline Mean* & $0.883(0.780-0.985)$ & $1.406(1.295-1.518)$ & $2.010(1.894-2.125)$ & $3.014(2.906-3.123)$ \\
\hline \multicolumn{5}{|l|}{ Females } \\
\hline \multicolumn{5}{|l|}{ Model 1} \\
\hline Mean $(95 \% \mathrm{Cl})^{*}$ & $0.538(0.494-0.581)$ & $1.176(1.132-1.220)$ & $2.335(2.291-2.379)$ & $3.288(3.244-3.331)$ \\
\hline \multicolumn{5}{|l|}{ Model 2} \\
\hline Mean* & $0.840(0.794-0.885)$ & $1.255(1.214-1.297)$ & $2.220(2.178-2.262)$ & $3.011(2.966-3.056)$ \\
\hline \multicolumn{5}{|l|}{ Model 3} \\
\hline Mean* & $0.739(0.603-0.876)$ & $1.154(1.016-1.291)$ & $2.156(2.007-2.304)$ & $2.921(2.777-3.065)$ \\
\hline
\end{tabular}

predicting cardiovascular disease and diabetes mellitus in both sexes [38]. Therefore, clinical practitioners simply recommend that "your waist circumference should be less than half your height" [19]. The review with 147 individual analyses showed that the mean AUROC values for predicting metabolic syndrome were approximately $0.704,0.693$, and 0.670 for the WHtR, WC, and BMI, respectively. The review showed that the WHtR had the highest AUROC value followed by the WC, and then the BMI; however, the difference in the AUROC was small. The AUROC value for predicting metabolic syndrome, as well as the differences in AUROC between the WHtR and other indices, was greater in our study than in the previous review. In addition, our cut-off value was similar to that of the review. Therefore, the criteria for other population groups are applicable to the Korean population. In our data, logistic regression analyses by using a cut-off value of $\mathrm{WHtR}<0.5$ showed a significant association between WHtR $<0.5$ and metabolic syndrome or metabolic syndrome components.

The present study was based on a sub-sample of a nationwide representative survey. Approximately $57.7 \%$ of the total cohort were excluded from the study cohort. Additional file 1: Table S1 shows the baseline characteristics of the total cohort. Age and education level were lower in the total cohort than in the study cohort. Concerning the mean daily alcohol intake, a higher abstinence and lower heavy drinking was found in the total cohort than in the study cohort. The number of non-smokers was higher in the total cohort than in the study cohort. The amount of exercise was similar between the two cohorts. The age of participants was lower in the total cohort than in the study cohort. The participants' age may be associated with the differences in alcohol drinking, education level, and smoking status. The total cohort included 8,995 participants who were younger than 18 years. This exclusion may have caused older age in the study cohort than in the total cohort.

The present study has a number of limitations. First, it is limited by its cross-sectional nature and ethnic differences were not evaluated. This study design showed associations between the indices and metabolic diseases but could not establish the causality between the indices and metabolic syndrome, and the ability of the indices to predict metabolic diseases. Second, the present study has the probability of recall bias from a self-reporting questionnaire survey. The impact of these limitations is reduced by the large sample size in the present study, but did not offset the cross-sectional nature of the study. A prospective study including follow-up data is needed to show the cause-andeffect relations between indices and metabolic diseases.

\section{Conclusion}

Body indices using body composition analyzers have no advantage over classic body indices such as BMI and WHtR. Among the classic body indices, WHtR is most useful to predict the presence of metabolic syndrome in the Korean population. In addition, it is really cheap and safe, especially if compared with DEXA. 


\section{Additional file}

Additional file 1: Table S1. Baseline characteristics of the total cohort. Table S2. Comparison of AUROC for prediction of metabolic syndrome among variable indices. Table S3. Odds ratios for metabolic syndrome components according to the quartiles of variable indices. Table S4. Odds ratios for metabolic syndrome components according to the quartiles of variable indices. (DOCX $29 \mathrm{~kb}$ )

\section{Abbreviations}

WC: Waist circumference; BMI: Body mass index; WHtR: Waist to height ratio; DEXA: Dual-energy X-ray absorptiometry; FM: Fat mass; KNHANES: Korean National Health and Nutrition Examination Survey; LM: Lean mass; TFM: Trunk fat mass; BMC: Bone mineral content; eGFR: Estimated glomerular filtration rate; MET min/wk: Metabolic equivalent-minutes per week; PYR: Average daily smoking amount [pack] × smoking period [year]; Cl: Confidence interval; AUROC: Area under the receiver operating characteristic curve; Q1: First quartile; Q2: Second quartile; Q3: Third quartile; Q4: Fourth quartile.

\section{Competing interests}

The authors declare that they have no competing interests.

\section{Authors' contributions}

SHK contributed to conception and design and interpretation of data. SHK, $\mathrm{KHC}$, and JWP were involved in drafting of the manuscript. SHK and JYD were involved in revising the manuscript and final approval of the version to be published. All authors read and approved the final manuscript.

\section{Acknowledgments}

We do not have someone to acknowledge.

This manuscript has not been submitted elsewhere. All authors took part in the work and agree with the contents of the manuscripts.

Received: 6 March 2015 Accepted: 1 December 2015 Published online: 08 December 2015

\section{References}

1. Grundy SM, Cleeman JI, Daniels SR, Donato KA, Eckel RH, Franklin BA, et al. National Heart, Lung, and Blood Institute. Circulation. 2005;112:2735-52.

2. Reaven GM. Banting lecture 1988. Role of insulin resistance in human disease. Diabetes. 1988;37:1595-607.

3. Ford ES, Giles WH, Dietz WH. Prevalence of the metabolic syndrome among US adults. JAMA. 2002;287:356-9.

4. Isomaa B, Almgren P, Tuomi T, Forsén B, Lahti K, Nissén M, et al. Cardiovascular morbidity and mortality associated with the metabolic syndrome. Diabetes Care. 2001;24:683-9.

5. Lakka HM, Laaksonen DE, Lakka TA, Niskanen LK, Kumpusalo E, Tuomilehto J, et al. The metabolic syndrome and total and cardiovascular disease mortality in middle-aged men. JAMA. 2002;288:2709-16.

6. Ashwell M, Cole TJ, Dixon AK. Ratio of waist circumference to height is strong predictor of intra-abdominal fat. Br Med J. 1996;313:559-60.

7. Cox BD, Whichelow M. Ratio of waist circumference to height is better predictor of death than body mass index. Br Med J. 1996;313:1487.

8. Hsieh SD, Muto T. Metabolic syndrome in Japanese men and women with special reference to the anthropometric criteria for the assessment of obesity: Proposal to use the waist-to-height ratio. Prev Med. 2006;2006(42): 135-9.

9. Sawa SC, Lamnisos D, Kafatos AG. Predicting cardiometabolic risk: waist-toheight ratio or BMI. A meta-analysis. Diabetes Metab Syndr Obes. 2013;6: 403-19.

10. Atlantis E, Martin SA, Haren MT, Taylor AW, Wittert GA, Members of the Florey Adelaide Male Ageing Study. Inverse associations between muscle mass, strength, and the metabolic syndrome. Metabolism. 2009;58:1013-22.

11. Park BS, Yoon JS. Relative skeletal muscle mass is associated with development of metabolic syndrome. Diabetes Metab J. 2013;37:458-64.

12. Liu P, Ma F, Lou H, Liu Y. The utility of fat mass index vs. body mass index and percentage of body fat in the screening of metabolic syndrome. BMC Public Health. 2013;13:629.
13. Rothney MP, Catapano AL, Xia J, Wacker WK, Tidone C, Grigore L, et al. Abdominal visceral fat measurement using dual-energy $X$-ray: association with cardiometabolic risk factors. Obesity. 2013;21:1798-802.

14. Kim JY, Oh S, Chang MR, Cho YG, Park KH, Paek YJ, et al. Comparability and utility of body composition measurement vs. anthropometric measurement for assessing obesity related health risks in Korean men. Int J Clin Pract. 2013;67:73-80.

15. Namwongprom S, Rerkasem K, Wongthanee A, Pruenglampoo S, Mangklabruks A. Relationship between body composition parameters and metabolic syndrome in young Thai adults. J Clin Res Pediatr Endocrinol. 2014;6:227-32

16. Sagun G, Oguz A, Karagoz E, Filizer AT, Tamer G, Mesci B. Application of alternative anthropometric measurements to predict metabolic syndrome. Clinics (Sao Paulo). 2014;69:347-53.

17. Mooney SJ, Baecker A, Rundle AG. Comparison anthropometric and body composition measures as predictors of components of the metabolic syndrome in a clinical setting. Obes Res Clin Pract. 2013;7:e55-66.

18. Zhang ZQ, Deng J, He LP, Ling WH, Su YX, Chen YM. Comparison of various anthropometric and body fat indices in identifying cardiometabolic disturbances in Chinese men and women. PLoS One. 2013;8:e70893.

19. Jowitt LM, Lu LW, Rush EC. Migrant Asian Indians in New Zealand; prediction of metabolic syndrome using body weights and measures. Asia Pac J Clin Nutr. 2014;23:385-93

20. Levey AS, Stevens LA, Schmid CH, Zhang YL, Castro 3rd AF, Feldman HI, et al. A new equation to estimate glomerular filtration rate. Ann Intern Med. 2009;150:604-12

21. Craig CL, Marshall AL, Sjöström M, Bauman AE, Booth ML, Ainsworth BE, et al. International physical activity questionnaire: 12-country reliability and validity. Med Sci Sports Exerc. 2003;35:1381-95.

22. Hwang GY, Cho YJ, Chung RH, Kim SH. The Relationship between Smoking Level and Metabolic Syndrome in Male Health Check-up Examinees over 40 Years of Age. Korean J Fam Med. 2014;35:219-26.

23. Rehm J, Room R, Monteiro M, Gmel G, Graham K, Rehn N, et al. Jernigan D Alcohol use in Ezzati M, Lopez A, Rodgers A, Murray CJL eds Comparative Quantification of Health Risks: global and regional burden of disease attributable to selected major risk factors. Geneva: World Health Organization; 2004. p. 959-1108.

24. The Korea Centers for Disease Control and Prevention: Alcohol drinking. [internet]. Available from: http://health.mw.go.kr/HealthlnfoArea/Healthlnfo/ View.do?idx=5800\&subldx=3\&searchCate $=\&$ searchType $=\&$ searchKey $=$ \&pageNo=\&category=1\&category_code=301301306\&dept=3\&sortType= date\&page $=1 \&$ searchField=titleAndSummary\&searchWord

25. Després JP, Moorjani S, Lupien PJ, Tremblay A, Nadeau A, Bouchard C. Regional distribution of body fat, plasma lipoproteins, and cardiovascular disease. Arteriosclerosis. 1990;10:497-511.

26. Pouliot MC, Després JP, Nadeau A, Moorjani S, Prud'Homme D, Lupien PJ, et al. Visceral obesity in men. Associations with glucose tolerance, plasma insulin, and lipoprotein levels. Diabetes. 1993;41:826-34.

27. Schreiner PJ, Terry JG, Evans GW, Hinson WH, Crouse 3rd JR, Heiss G. Sex-specific associations of magnetic resonance imaging-derived intra-abdominal and subcutaneous fat areas with conventional anthropometric indices. The Atherosclerosis Risk in Communities Study. Am J Epidemiol. 1996;144:334-45.

28. Ma WY, Yang CY, Shih SR, Hsieh HJ, Hung CS, Chiu FC, et al. Measurement of Waist Circumference: midabdominal or iliac crest? Diabetes Care. 2013;36:1660-6.

29. Henriksson KM, Lindblad U, Ågren B, Nilson-Ehle P, Råstam L. Associations between body height, body composition and cholesterol levels in middleaged men. The coronary risk factor study in southern Sweden (CRISS). Eur J Epidemiol. 2001;17:521-6.

30. Wannamethee SG, Shaper AG, Morris RW, Whincup PH. Measures of adiposity in the identification of metabolic abnormalities in elderly men. Am J Clin Nutr. 2005;81:1313-21.

31. Menke A, Muntner P, Wildman RP, Reynolds K, He J. Measures of adiposity and cardiovascular disease risk factors. Obesity. 2007;15:785-95.

32. Lee K, Song YM, Sung J. Which obesity indicators are better predictors of metabolic risk?: healthy twin study. Obesity. 2008;16:834-40.

33. Dai S, Eissa MA, Steffen LM, Fulton JE, Harrist RB, Labarthe DR. Associations of BMI and its fat-free and fat components with blood lipids in children: Project HeartBeat! Clin Lipidol. 2011;6:235-44.

34. Barsalani R, Brochu M, Dionne IJ. Is there a skeletal muscle mass threshold associated with the deterioration of insulin sensitivity in sedentary lean to obese postmenopausal women? Diabetes Res Clin Pract. 2013;102:123-8. 
35. Bosy-Westphal A, Geisler C, Onur S, Korth O, Selberg O, Schrezenmeir J, et al. Value of body fat mass vs anthropometric obesity indices in the assessment of metabolic risk factors. Int J Obes. 2006;30:475-83.

36. Baron AD, Brechtel G, Wallace P, Edelman SV. Rates and tissue sites of noninsulin- and insulin-mediated glucose uptake in humans. Am J Physiol. 1988;255:E769-74.

37. Weber DR, Leonard MB, Shults J, Zemel B. A Comparison of Fat and Lean Body Mass Index to BMl for the Identification of Metabolic Syndrome in Children and Adolescents. J Clin Endocrinol Metab. 2014;99(9):3208-16.

38. Browning LM, Hsieh SD, Ashwell M. A systematic review of waist-to-height ratio as a screening tool for the prediction of cardiovascular disease and diabetes: 0.5 could be a suitable global boundary value. Nutr Res Rev. 2010; 23:247-69.

Submit your next manuscript to BioMed Central and we will help you at every step:

- We accept pre-submission inquiries

- Our selector tool helps you to find the most relevant journal

- We provide round the clock customer support

- Convenient online submission

- Thorough peer review

- Inclusion in PubMed and all major indexing services

- Maximum visibility for your research 